\title{
Exploring How Blockchain Impacts Loyalty Program Participation Behaviors: An Exploratory Case Study
}

\author{
Lu Wang \\ University of \\ International Business \\ and Economics, China \\ wanglu@uibe.edu.cn
}

\author{
Xin (Robert) Luo \\ University of New \\ Mexico, USA \\ xinluo@unm.edu
}

\author{
Ying Hua \\ University of \\ International Business \\ and Economics, China \\ cissyhy@126.com
}

\author{
Jing Wang \\ Bubi Technologies Co., \\ Ltd, China \\ wangjing@bubi.cn
}

\begin{abstract}
How to keep customers motivated in participative behaviors remains one major challenge in extant loyalty program (LP) studies. While some companies have initiated efforts to utilize blockchain-based distributed ledgers and smart contract capabilities to enhance customer experience and improve LP efficiencies, academic assessment of blockchain application in the LP context remains scarce. This research attempts to establish a theoretical overview of how the key natures of blockchain influence customers' varying motivations (economy, autonomy, competence and relatedness) and perceived value, which consequently induce participative behaviors in a loyalty points context. Then, using an exploratory case study of Bubichain in China, we verify that the blockchain-enabled loyalty points scheme not only improves customers' economic perceived value by meeting their economic motives, as the traditional one does, but also enhances their social interaction and psychological self-fulfillment value perception by meeting their intrinsic motivations, thus increasing customers' experience and participation behaviors.
\end{abstract}

\section{Introduction}

There is growing evidence that consumers are becoming disenchanted with the reward they receive for their effort in earning loyalty points (Alejandro, Kang and Groza 2016). A recent Statista survey shows that the share of active loyalty program (LP) memberships in the U.S. kept around only $45 \%$ during 2014-2016 (Statista 2017). In China, only less than half of the credit card points had been converted into purchase by 2015 , yielding a waste of value over $\$ 3.1$ billion. In a bid to enhance customer engagement and stay abreast of competition, companies are becoming increasingly creative in their loyalty points scheme design (Zhang and Breugelmans, 2012). However, performance of the efforts rarely meets expectations, especially the low activeness of LP participation
(Dowling and Uncles, 1997; Ferguson and Hlavinka, 2007; Kreis and Mafael, 2014). Reward points program is usually considered as an economic incentive, which enhances customer experiences and purchase retentions by bringing instrumental benefits of financial advantages (Mägi, 2003; Peterson, 1995). However, extant studies have revealed that extrinsic (e.g. economic) rewards may undermine motivation and behaviors while intrinsic benefits tend to have a positive effect (Meyer-Waarden, 2013; Deci et al. 1999). Therefore, new viewpoints and welfare benefits of consumers are needed in the loyalty points context (Lacey and Sneath, 2006), and this paper attempts to explore new LP designs based on IT applications, which focus on enhancing customers' participative behaviors.

Blockchain is viewed as one of the most innovative technological artifacts that will influence and morph business and society in the years to come (Webb, 2015; Kim and Laskowski, 2017). Business service providing giants such as IBM, Deloitte, and Accenture have been working on using blockchain to alleviate the current plights of loyalty points scheme by reducing operating costs, accommodating multi-brands partnerships, and improving customer experience. However, as an emerging digital technology, both conceptual expositions and empirical evidence about how the blockchain applications improve LPs are deficient (Kshetri 2018). In essence, scholars have not systematically assessed the effects of blockchain on LPs because the blockchain deployment has been still largely experimental. The paucity of scientific knowledge in this growing yet important field no doubt warrants further investigations in LPs management. Our study is an early attempt to explore a theoretical underpinning and empirical knowledge about the way blockchain application influences customer LP engagement. Our research objective is to develop an in-depth understanding of the value perception in the context of blockchain-enabled LP participation. We attempt to accomplish our research objective through an exploratory case study of a 
blockchain-based platform that offers loyalty point management services for brands and customers.

The rest of the article is organized as follows: First, we discuss the pertaining literature and present our theoretical pre-understanding on LP design, customer motivations, value perception, and blockchain techniques. Followed is a description of our case organization, a brief discussion of the methodology employed in this study, and the interpretation of the case study data. We conclude with a discussion of the limitations, future directions and the study's key conclusions.

\section{Theoretical foundations}

\subsection{Self-Determination Theory and customer motivations}

According to existing research (e.g. Shugan, 2005), one primary reason why customers are becoming less interested in loyalty points is that their personal preferences and needs are not satisfied in the current LP schemes. Loyalty points are in terms of future rewards or deferred rebates, and customers are usually limited on where and when they can spend them. Due to the motivational variations that are potentially associated with LP participation behaviors, Self-Determination Theory (SDT) is an appropriate theory (Ryan and Deci, 2002) for this study.

SDT offers a theoretical framework to explain that individuals are motivated to satisfy their various basic needs and postulates two types of motivation: intrinsic and extrinsic motivation (Deci and Ryan 1985). The term intrinsic motivation relates to the inherent satisfactions of doing an activity (e.g. humans' natural tendency to engage in interesting and playful activities) (Kim and Ahn, 2017) whereas the term extrinsic motivation refers to the goal of obtaining tangible rewards or external outcomes of executing an activity (Ryan and Deci, 2000).

Based on SDT, we define customers motivations for LP participation as the following four dimensions: Economy (extrinsic motivation, a sense of saving money from LP activates), Autonomy (intrinsic motivation, a sense of internal assent of one's own actions and behaviors), Competence (intrinsic motivation, a sense of feeling effective and capable in exercising and expressing personal capabilities), and Relatedness (intrinsic motivation, a sense of connection and interaction with others) (Ryan and Deci, 2002; Shi et al., 2014; Meyer-Waarden, 2013).

\subsection{Customer perceived value}

SDT implies that various reward designs and contexts affect motivation differently, while consumers' motivations have influence on increasing the perceived value of partaking a LP and thus act as a cognitive driver of subsequent participation behaviors (Wyer and Xu, 2012; Woodruff, 1997; Polo and Sesé, 2009). We connect the customer motivations with actual value perception that results from satisfying these needs. When a LP is designed to be effective (cheaper, easier, faster, and/or more secure over points accruing and redemption), then it can deliver varying perceived value to different customers.

To obtain a detailed understanding of how customer motivations and value perception are connected, it is necessary to consider customer value as a multidimensional, personalized concept. In a theoretical review paper of LP effectiveness, scholars argue that LP-induced change to consumer behaviors typically results from customers' mental processes (Henderson, Beck and Palmatier, 2011). Based on previous research (Sheth et al., 1991; Sweeney and Soutar, 2001; Kreis and Mafael, 2014), we propose three mental categories of value perception: Economic utility (primarily relates to and stems from financial advantages, such as price discount or gifts offering, and can be connected with extrinsic motivations). Psychological self-fulfillment (emphasizes a product's ability to enhance customer's self-concept and can be connected with intrinsic motivations), and Social interaction (can be derived from feelings of belonging to a community/like-minded peers or having relationship with a brand or company, and can be connected with intrinsic motivations).

\subsection{The role of LPs design in LP efficiency}

Recent research about LPs effectiveness focuses on accounting for LPs design elements (choices, requirements, deadlines, and reward options) as a feasible approach to the controversies concerning the usefulness of LPs for value creation (Evanschitzky et al., 2011; Kumar and Shah, 2004). LPs vary enormously in their design, which exerts an impact on LP effectiveness (d'Astous and Landreville 2003; Liu and Yang, 2009; Nunes and Dreze, 2006; Zhang and Breugelmans, 2012). Several studies have looked at the design of LPs to examine how much a consumer has to spend to receive a loyalty point (e.g. Dorotic et al., 2012; Roehm et al., 2002), whereas some other studies have examined the fairness of redeeming loyalty points based on equity theory (Kwong et al., 2011; Danaher et al., 2016). Furthermore, a variety of studies base their analyses on psychological mechanisms and examine the undermining effects of extrinsic rewards on intrinsic motivation in the context of LPs (Kim, Shi, and Srinivasan 2001; Kim and Ahn, 
2017). However, the extant studies rarely take IT factors into consideration as a key resource of LP design for enhancing LP effectiveness, although in recent years more and more companies adopt IT application into supplying better services and improving customer experiences.

\subsection{Key Techniques of Blockchain in LP design}

One of the most discussed and disruptive innovations nowadays is blockchain, which is described as a distributed database technology that facilitates verified, tamper-resistant transactions across network participants (Glaser, 2017; Beck et al, 2018). In contrast to the traditional trust mechanism where a central party (e.g. an insurance company, a central bank, or the government) is needed, blockchain is a "trust-free" solution, where the technical part assures the transactions not to be altered as long as it is logged on the blockchain. If the data is changed, no transaction will take place, which makes the system inherently secure (Beck et. al, 2016).

Business and IT service providers (e.g. IBM, Deloitte and Fujitsu) have launched blockchain-based data storage system that can be used by merchants to tokenize their loyalty points. Typically, the system is supposed to be integrated with the promotional activities of merchants in shopping centers or chain restaurants that allow consumers to spend digital points received from one store at different outlets. Within such a system, consumers purchase goods and services with points obtained from flight mileage, hotel bonus, gas cards, and retailer rewards at near real-time, or transfer their points to peers. However, many of the blockchain-based LP projects remain in corporate announcements of intention, while few are currently in deployment.

Blockchain is a class of particular technologies which are called distributed ledger technologies, including hash values (used to validate the block's integrity, any changes to the transactions that make up a block will alter the hash value of the block as a whole), asymmetric key encryption (used to create and authenticate identities on the blockchain), and peerto-peer networks (decentralized and interconnected network that shares tasks between all participants equally which allows for redundancy of the data in the blockchain) (Beck et. al, 2018; Jaikaran, 2018). Little is known about the implications of blockchain for customers' loyalty point activities. Blockchain could give rise to a tokenized economic system, which is able to enhance the feasibility and fungibility of digital assets by making it easier and faster for customers to access and consume them.

From a resource-based view, IT or its applications play a significant role in enabling firms to offer superior services and consequently deepen the relationships with their customers (Melville et al., 2004; Ray et al., 2005; Zhang et al., 2011). The core of the theoretical analysis of this research is to explore how blockchain, as an information technology on the rise, influences value creation in a LP context.

Motivation analysis based on SDT has already been applied in the context of education (e.g., Shi et al., 2014; Dadiz and Baldwin, 2016), pro-social behavior (e.g., Osbaldiston and Sheldon 2003; Weinstein and Ryan 2010), and customer loyalty (Kim and Ahn, 2017; Meyer-Waarden, 2013; O'Donnell and Brown, 2012). This paper considers both extrinsic and intrinsic motivations in a LP context guided by SDT regulation: meeting the needs of Economy, Autonomy, Competence and Relatedness, and exploring how these motivations can be affected by blockchain techniques, thus influencing subsequent value perception and customer behaviors (see Figure 1).

\section{Case Study and Methodology}

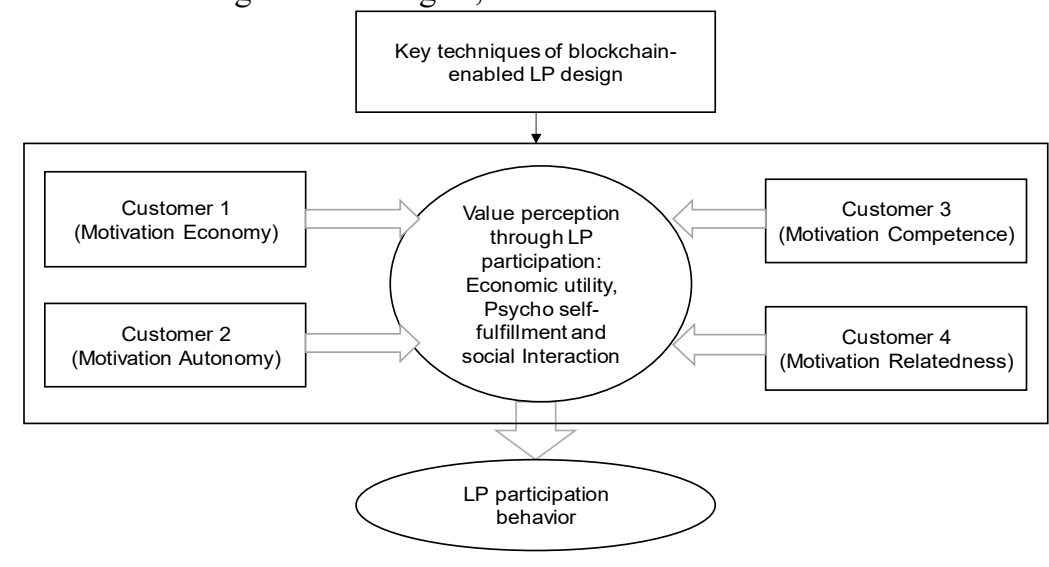

Figure 1. Literature-based pre-understanding of the effects of blockchain on LP participation behaviors. 


\subsection{Case Background}

Bubi Technologies Co., Ltd. (Beijing, China) is a leading blockchain fintech company in China (www.bubi.cn), which focuses on blockchain technology development and product innovation. Bubi began to engage in blockchain technology R\&D early in 2012, and the company was officially established in March 2015. In December 2015, Bubi launched the first blockchain business application in China, which is a loyalty point platform based on Bubichain, a blockchain independently developed by Bubi company.

Holding dozens of core patented technologies, Bubichain has currently been used in the management of digital assets, trade finance, equity bonds, supply chain traceability, loyalty points, joint credit, public notarization, electronic invoices, and data security, and carried out trials and testing at major financial institutions such as exchanges and banks. By the end of 2017, Bubi has completed an A-round financing that exceeded \$25 million.

The reason why we chose Bubichain as a single case is that many of the current blockchain-based LP projects still remain in corporate announcements of intention, while Bubichain has successfully deployed one its projects for a shopping district in Guangdong province, China. 209 brands of the shopping district have accumulated just 2,000 members during the last two years. But after Bubichain was deployed in February 2018, it has attracted over 20,841 customers to use the blockchain-based point cards within one week, according to Mr. Xiaogang Huang, the Manager of Loyalty Point Business of Bubi.

\subsection{Methodology}

In line with past research (Kotlarsky, 2007; Yin, 1994), an exploratory case study method was selected for this research. An in-depth case study of Bubichain loyalty point platform was carried out.

We adopted a qualitative, interpretive approach, and the main goal of the empirical research is to explore:

1. What characteristics does the blockchain-based LP platform have, based on the key techniques of blockchain?

2. How do the specific blockchain characteristics influence the value perception of customers with different motivations?

Intensive data was collected through semistructured interviews and other documentary evidence (Sarker et al., 2012). Interviews (face-to-face or on telephone) focusing on the value perception phenomenon surrounding blockchain-based LP context guided by SDT were conducted on April 11, 2018, and lasted for one week.

This process led to the discovery of the effects of blockchain on value perception for different motivated customers. In understanding the role of the key natures of blockchain-based LP scheme, we first conducted the interviews with 3 representatives from Bubi company, and by examining the data we identified the key characteristics of Bubichain that respondents mentioned. Next, we conducted the interviews with over 10 customers, under the four major theoretical categories of SDT motivations (economy, autonomy, competence and relatedness), and attempted to discern cause-effect relations between blockchain characteristics and customer perceived value.

\section{Interpretation and results}

\subsection{The key characteristics of Blockchain- based LP design}

The first notable issue is to examine the key characteristics of the blockchain-enabled LP design, which is rarely seen in extant literature. The question is "what characteristics does Bubichain point platform have, compared to the non-blockchain platform?"

To start with, Mr. Jingfeng Jiang, an engineer of Bubi, introduced the natures of Bubichain: "Bubichain is a blockchain technology infrastructure independently developed by Bubi's core team from 2012, whose source code is open licensed on GitHub. It has multiple branches and is constantly being updated. Bubichain is capable of providing high scalability, high performance and high controllability of blockchain basic services and building upper-layer application services to meet the needs of large-scale users. Sunshine Life Insurance, People's Insurance Company of China, CITIC Group, Haier Financial Holdings and other large companies are Bubichain's initial users and have built their digital assets (e.g. loyalty points) on the mid-term Bubichain support system."

Dr. Jun $\mathrm{Li}$, the Co-founder and $\mathrm{COO}$ of Bubi, highlighted the main characteristics of the loyalty points platform based on Bubichain: "First, Bubichain's distributed account and ledger structure enables multi-assets account, so the LP platform based on Bubichain is able to support multiple digital assets, whereas previous blockchains could only support one single asset. Second, based on programmable smart contracts, Bubichain allows loyalty point issuers to manage their points respectively. These points can be customized for expiration dates and other attributes. Third, Bubichain's account structure allows all points to be marked and given an unforgeable identity 
through algorithms such as real-name authentication. Therefore, the platform has the ability to provide multiple levels of security and achieve rights management. Finally, Bubichain's transaction confirmation time does not exceed 1 second (32 nodes, 4 core 8G memory, $100 \mathrm{M}$ bandwidth), so the transaction can be verified near real time."

Mr. Xiaogang Huang, the Manager of Loyalty Points Business of Bubi said: "On the one hand, points issued on Bubichain platform are asset-type, which can be given, merged, consumed, and circulate conveniently. In the past, consumers accrued and consumed points in one store, but could not use them in other stores. Now on Bubichain platform, points can circulate from one store to another, so consumers can redeem the points of one store at another store by their preference, and even transfer to other individuals. On the other hand, the points issued by each merchant cannot be forged, falsified or deleted. Point on Bubichain platform have its unique identification, and the circulation of it can be tracked and stored on the entire network. Even if $99 \%$ of the networks are shut down, the point information would not be lost. Therefore, customer's dominance of points and value are increased."

We now outline the main key characteristics of blockchain-enabled LP design as follows: Real-time exchange (realizes near-real-time exchange and redemption of rewards points, by lowering the amount of time [to seconds] firms take to process transactions and data), Multi-brands exchange (accommodates multiple brands and their LPs, while facilitating their interaction in terms of the convertibility and exchange of the points), Peer-to-peer exchange (allows the access to the connections with peers in social communities, and supports deals between individuals with reciprocal goals and demands), and finally Secure, traceable and fraud-proof exchange (creates an immutable and time-stamped distributed database entry for every single transaction, preventing double spending or any fraud, abuse of the transactions).

It is important to understand that the above natures are not exclusive for blockchain-based platform. For example, some non-blockchain platform can also support peer-to-peer exchange. But the blockchainbased platform possesses all the natures concurrently, that is, processing and confirming transactions upon a peer-to-peer network at near real-time while assuring tamper-resistant.

In the following, we discuss how the unique features of blockchain-based platform affect the customer motivations and subsequent behaviors.

\subsection{How blockchain natures impact LP participation}

Below we will explain the ways these blockchain natures influence LP engagement behaviors of customers, guided by SDT-based motivations.

4.2.1. Towards satisfying the need of Economy. Customer's economic motives could be satisfied when he feels that he pays better prices, acquires special gifts, gets more discounts than most customers, or just saves money or time by engaging in the LP (Long and Schiffman, 2000; Gwinner et al., 1998). Primarily, customer perceives economic utility value when his need of Economy is satisfied (e.g. it is economically reasonable for me to engage in points redemption, the LP offers me additional value for my money, etc.) (Mägi, 2003; Peterson, 1995).

Question in this part is: "Do you want to save/earn money on Bubichain point platform? How do you feel about it? And will you take part in it again?"

Some customer respondents explained that they perceived their economic value in the process of Bubichain LP activities, due to the near-time, multibrands and secure exchange natures of blockchain.

As Customer_\#1 noted: "Unbelievable! I can redeem my points into discount coupons on the Bubichain platform! I've never imagined this before!" Customer can earn, spend, or trade the points as an asset that is more relevant to their personal preferences, rather than a liability (Shugan, 2005).

As Customer_\#2 noted: "Last week, when I planned to prolong my vacation, I exchanged my extra airline points at a higher price on Bubichain, with the hotel points of another person, who was eager to get a timely flight. It's really amazing experience!" Obviously, the blockchain application with security and privacy enhances customers' economy utility value by saving/earning money.

As Customer_\#3 noted: "My bank points usually take days or even weeks to be available for redemption, so that I sometimes forgot about them. What a loss! Now it seems faster and easier to use points, which saves my money and time." Blockchain-based nearreal-time LP has a strong focus on the economic motivation and, consequently, add economic utility value to a customer's decision to engage the specific LP repeatedly.

4.2.2. Towards satisfying the need of Autonomy. Customer's autonomy motives could be satisfied when he purchases under a specific goal that he sets on his own, achieves rewards by no certain due date, or has choices and options in choosing rewards (Deci, Connell and Ryan, 1989). Primarily, customer perceives psychological self-fulfillment value when his need of Autonomy is satisfied (e.g. the LP helps me feel better about myself, I think I deserve to be rewarded for my purchases, I enjoy being a member of 
the LP, etc.) (Minouni-Chabaane and Volle, 2010; Sweeney and Soutar, 2001).

Question in this part is: "Do you want to have your own choices on Bubichain point platform? How do you feel about it? And will you take part in it again?"

Some customer respondents explained that their autonomy needs were met and perceived psychological self-fulfillment value, due to the multibrands, peer-to-peer and secure exchange natures of blockchain.

As Customer_\#4 noted: "In the past, I could only redeem the points in this store or its branches. Now I really feel better when I'm able to consume points at other stores and have more choices, even giving the points to my friends." An environment that supports the need for autonomy is likely to allow a customer to have choices as a means of expressing himself. Therefore, the blockchain-enabled LP system, with flexible choices and options in choosing rewards and seamless exchange process across individuals, customer perceives a psychological value of selffulfillment by feeling that his behavior is based on his own intention (Shi et al., 2014).

As Customer_\#5 noted: "I've ever purchased in a store before and obtained points, but when I visited the store again after a long time, I found my points disappeared! I doubt they have been eliminated by that store. Now I don't worry about it, because I know that blockchain is such a technique that records cannot be tampered or forged, so I don't need to worry whether my points would be removed by someone." The need for autonomy refers to an individual's perception of how much he has control over the action, so the secure, traceable and fraud-proof nature of blockchainenabled LP can make customer feel in control and perceive the self-fulfillment value.

\subsubsection{Towards satisfying the need of Competence.} Customer's competence motives could be satisfied when he feels interested to engage in the loyalty program, feels being encouraged to achieve rewards, has control on the progress toward reward achievement, or has fun and surprise to engage in the loyalty program (Ryan, 1982; Ryan and Deci, 2016). Primarily, customer perceives psychological selffulfillment value when his need of Competence is satisfied.

Question in this part is: "Do you want to make your efforts on Bubichain point platform? How do you feel about it? And will you take part in it again?"

Some customer respondents explained that their competence needs were met and perceived psychological self-fulfillment value, due to the neartime, multi-brands and peer-to-peer exchange natures of blockchain.
As Customer_\#6 noted: "In the past I always forgot about my points, but now Bubichain always reminds me to use my points and I never forget about it because they seem as my own assets! I'll definitely join it again!"

As Customer_\#7 noted: "The rules of Bubichain motivates me to put more effort into point activities and it's really novel for me! I'm so pleased to be a member on the platform!"

The customer with need for competence regularly pursues the rewards for fulfilling a desire or a goal. When he is motivated to make efforts for an activity and his own behaviors turn to the cause of satisfied consequences, he represents a positive emotional response, such as feelings of pleasure or enjoyment (Zeithaml, 1988). Apparently, if a customer with competence motivation is satisfied by his own choices of the reward options or transaction objects, he tends to perceive more value of psychological selffulfillment. Besides, since the perceived value of fulfillment is defined as the balance between the perceived benefits and the perceived costs of attaining these benefits (Meyer-Waarden, 2013), so a faster and easier system featured with real-time exchange really works.

4.2.4. Towards satisfying the need of Relatedness. Customer's competence motives could be satisfied when he has opportunities to discover and join communities or has connections of interest and goals between peers and communities (Ryan and Deci, 2000; Shi et. al., 2014). Primarily, a customer perceives social interaction value when his need of Relatedness is satisfied and can be derived from feelings of belonging to a community/like-minded peers or having relationship with a brand or company (e.g. through the LP activities I can express my appreciation for the company or community, the LP has social benefits for me, etc.) (Kreis and Mafael, 2014).

Question in this part is: "Do you want tointeract with others on Bubichain point platform? How do you feel about it? And will you take part in it again?"

Some customer respondents explained that their relatedness needs were met and perceived social interaction value, due to the peer-to-peer exchange natures of blockchain.

As Customer_\#8 noted: "In the past, I sometimes had no idea how to use these points, now I can just directly transfer the points to other people. Last month, I gave my uncle 500 sunshine points (issued by Sunshine Life Insurance) on Bubichain and it made him very happy! That's terrific!"

As Customer_\#9 noted: "I have accumulated many points, while having no time to consume them. Then I gave all of them to my friends." The need for relatedness means feeling connected to peers. The 


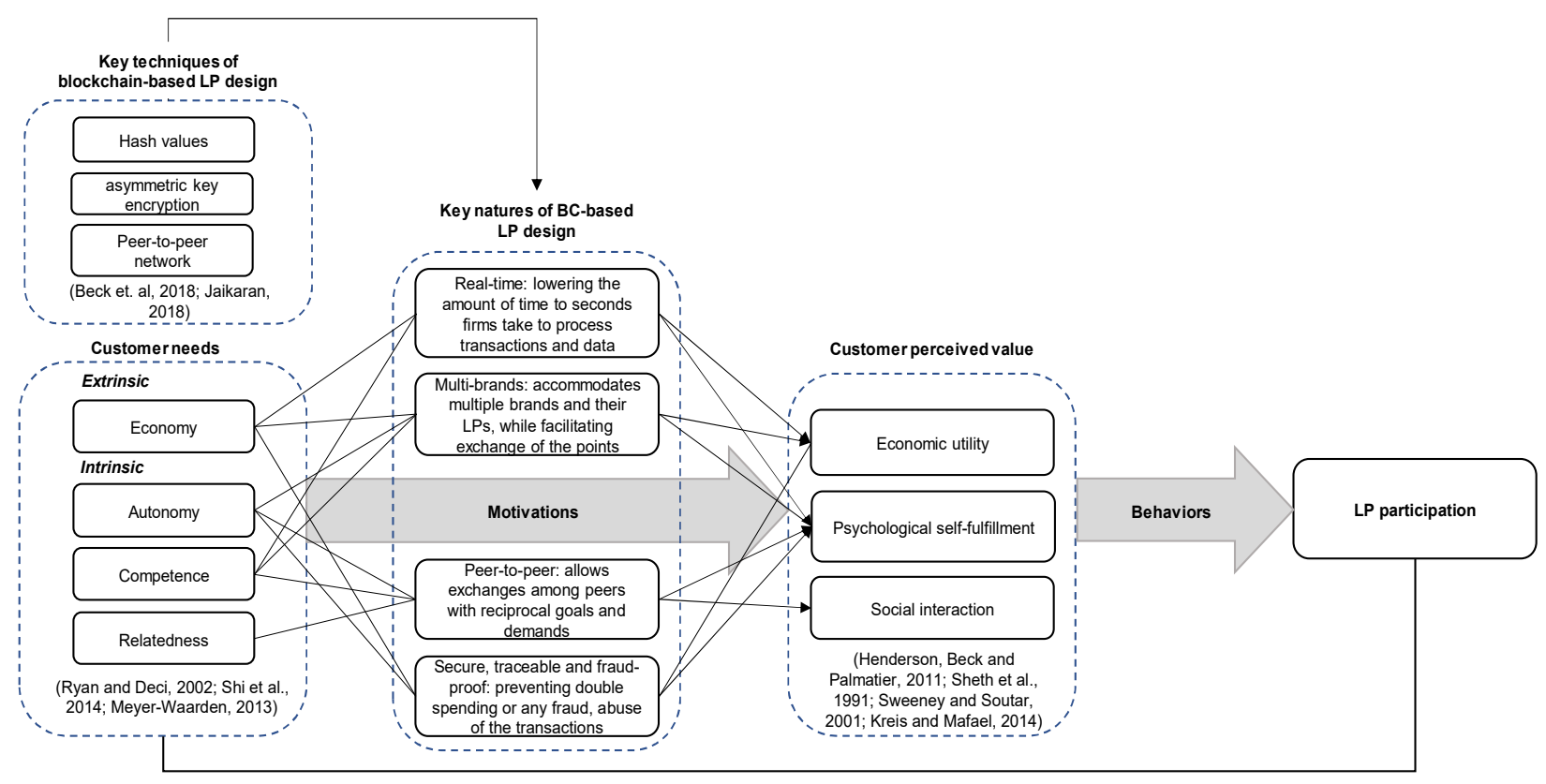

Figure 2. Overview of the effects of blockchain on LP participation

social interactions among peers provide a customer with opportunities to join the surrounding community and make him feel more related. Relatedness can be enhanced by connecting customers to a community with the same interest or goals. For a consumer with relatedness needs, the LP that allows point exchanges across individuals with reciprocal goals and demands can act as a powerful facilitator for the creation of social interaction value.

To summarize, key technique resources of blockchain convert to blockchain-based LP design natures that change the LP process, and act as facilitators for the creation of value. Specifically, while blockchain-based LP design natures influence the motives for LP participation, perceived value that relates to a certain motive embodies the assessment of the utility of the LP to satisfy the need. See Figure 2.

\section{Limitations, conclusions and future work}

In this study, we explored the relationship of customer motivation and perceived value moderated by blockchain-enabled LP design. There are a few limitations: first, our theoretical framework still needs to be improved. We adopted SDT as the theoretical foundation but did not achieve breakthrough on this theory, and the relationship between key techniques of blockchain and the key natures of blockchain-based LP design still remains vague. Future research needs to explore more new perspectives on the theoretical model; second, LP as an institutionalized incentive system itself could not directly lead to loyalty behaviors (Henderson et al., 2011). Future research needs to continue to explore the complicated relationships among blockchain-based LP design, LP engagement, and customer loyalty behaviors (e.g., purchase retention, word of mouth, etc.); third, this study used only one case to examine the conceptual model. Future studies are expected to employ multiple cases with various industries and regions to measure the impacts of blockchain on LP participation more comprehensively; finally, blockchain could entail high risks due to the potential problems including data portability, key securities or user collision and control. Future studies also need to explore failure cases and prove blockchain's application on a larger scale.

This study is an early attempt to analyze the blockchain impacts on LP, as it establishes a theoretical framework to explain the effect of blockchain in LP participative behaviors. We apply the self-determination theory for defining the needs for economy, autonomy, competence, and relatedness, while perceived value is categorized into three dimensions: economic utility, psychological selffulfillment, and social interaction. In a conceptual model, we explain the cause-effect of blockchain key techniques and the natures on the relationship of varying customer motivations and the corresponding perceived value. An exploratory case study on Bubichain platform for loyalty points management is adopted to scientifically prove that, while previous loyalty points scheme can only act as an economic incentive tool, the blockchain-enabled LP scheme is 
able to satisfy customers' multi-dimensioned motives due to its revolutionized natures. The blockchainbased LP can process and confirm transactions and data upon a peer-to-peer network at near real-time while assuring tamper-resistant, which is able to enhance the feasibility and fungibility of various digital assets by making it easier and faster for customers to access and consume them.

\section{Acknowledgements}

This paper is supported by "the Fundamental Research Funds for the Central Universities", No. $15 \mathrm{GD} 28$.

\section{References}

[1] Alejandro, T. B-, J. Kang, and M. D. Groza, "Leveraging Loyalty Programs to Build CustomerCompany Identification," Journal of Business Research (69:3), 2016, pp. 1190-1198.

[2] Baumeister, R. F., and K. D. Vohs, "Self-Regulation, Ego-Depletion, and Motivation," Social and Personality Psychology Compass (1:1), 2007, pp. 11528.

[3] Beck, R., J. S. Czepluch, N. Lollike, and S. O. Malone, "Blockchain - The Gateway to Trust-free Cryptographic Transactions," In the proceedings of 24th European Conference on Information Systems, 2016.

[4] Beck, R., C. Müller-Bloch, and J. L. King, "Governance in the Blockchain Economy: A Framework and Research Agenda," Working Paper, accepted in March 2018 for publication in the Journal of the Association for Information Systems, 2018.

[5] Dadiz, R., and C. D. Baldwin, "Educational Perspectives: Using Self-Motivation Strategies to Optimize Your Professional Learning," Neoreviews (17:4), 2016, pp. e188-e194.

[6] Danaher, P. J., Sajtos, L., and Danaher, T. S. 2016. "Does the Reward Match the Effort for Loyalty Program Members?" Journal of Retailing and Consumer Services (32), pp. 23-31.

[7] D'Astous, A, and V. Landreville, “An Experimental Investigation of Factors Affecting Consumers' Perceptions of Sales Promotions". European Journal of Marking (37:11/12), 2003, pp. 1746-1761.

[8] Deci, E.L., and R.M. Ryan, "The General Causality Orientations Scale: Self-determination in Personality," Journal of Research in Personality (19), 1985, pp. 109134.

[9] Deci, E. L., J. P. Connell, and R. M. Ryan, "SelfDetermination in a Work Organization," Journal of Applied Psychology (74:4), 1989, pp. 580-90.

[10] Deci, E. L., R. Koestner, and R. M. Ryan, "A MetaAnalytic Review of Experiments Examining the Effects of Extrinsic Rewards on Intrinsic Motivation," Psychological Bulletin (125:6), 1999, pp. 627-668.

[11] Dorotic, M., T.H.A. Bijmolt, , and P. C. Verhoef,
"Loyalty Programmes: Current Knowledge and Research Directions," International Journal of Management Review (14:3), 2012, pp. 217-247.

[12] Dowling, G. R., and M. Uncles, "Do Customer Loyalty Programs Really Work?" Sloan Management Review (38:4), 1997, pp. 71-82.

[13] Dreze, X., and J.C. Nunes, "Using Combined-currency Prices to Lower Consumers' Perceived Cost," Journal of Marketing Research (41:1), 2004, pp. 59-72.

[14] Evanschitzky, R., B. Ramaseshan, D.M. Woisetschläger, V. Richelsen, M. Blut, and C. Backhaus, "Consequences of Customer Loyalty to the Loyalty Program and to the Company," Journal of the Academy of Marketing Science (40:5), 2011, pp. 625638.

[15] Ferguson, R., and K. Hlavinka, "The colloquy loyalty marketing census: Sizing up the us loyalty marketing industry," Journal of Consumer Marketing (24:5), 2007, pp. 313-321.

[16] Glaser, F., "Pervasive Decentralisation of Digital Infrastructures: A Framework for Blockchain enabled System and Use Case Analysis," In Proceedings of the 50th Hawaii International Conference on System Sciences, 2017, pp. 1543-1552.

[17] Gwinner, K. P., D. D. Gremler, and M. J. Bitner, "Relational Benefits in Services Industries: the Customer's Perspective," Journal of Academy Marketing Science (26:2), 1998, pp. 101-114.

[18] Henderson, C.M., J. T. Beck, , and R. W. Palmatier, "Review of the Theoretical Underpinnings of Loyalty Programs," Journal of Consumer Psychology (21), 2011, pp. 256-276.

[19] www.bubi.cn

[20] http://finance.china.com.cn/roll/20170615/4248717.s html, Jule 15, 2017.

[21] Jaikaran, C., "Blockchain: Background and Policy Issues," Congressional Research Service. https://fas.org/sgp/crs/misc/R45116, February 28, 2018.

[22] Kim, B-D., M. Shi, and K. Srinivasan, "Reward Programs and Tacit Collusion," Marketing Science (20:2), 2001, pp. 99-120.

[23] Kim, H., and M. Laskowski, "A Perspective on Blockchain Smart Contracts: Reducing Uncertainty and Complexity in Value Exchange," International Conference on Computer Communication and Networks. IEEE, 2017.

[24] Kim K., and S. J. Ahn, "The Role of Gamification in Enhancing Intrinsic Motivation to Use a Loyalty Program," Journal of Interactive Marketing (40), 2017, pp. 41-51.

[25] Kotlarsky, J., I. Oshri, J. van Hillegersberg, K. Kumar, "Globally distributed component-based software development: An exploratory study of knowledge management and work division," Journal of Information Technology (22:2), 2007, pp. 161-173.

[26] Kreis, H. and A. Mafael, "The Influence of Customer Loyalty Program Design on the Relationship between Customer Motivations and Value Perception," Journal of Retailing and Consumer Services (21), 2014, pp. 590-600

[27] Kshetri, N., "Blockchain's Roles in Meeting Key 
Supply Chain Management Objectives," International Journal of Information Management (39), 2018, pp. 80-89.

[28] Kumar, V., D. Shah, "Building and Sustaining Profitable Customer Loyalty for the 21st Century," Journal of Retailing (80:4), 2004, pp. 317-330.

[29] Kwong, J.Y.Y., D. Soman, and C.K.Y. Ho, "The Role of Computation a Lease on the Decision to Spend Loyalty Program Points," Journal of Consumer and Psychology (21:2), 2011, pp. 146-156.

[30] Liu, Y. and R. Yang, "Competing the Influence of Loyalty Programs and Short-term Promotions on Customer Retention,” Journal of Marketing Research (73:1), 2009, pp. 93-108.

[31] Long, M. M. and L. G. Schiffman, "Consumption values and relationships: segmenting the market for frequency programs," Journal of Consumer Marking (17:3), 2000, pp. 214-232.

[32] Mägi, A.W., "Share of Wallet in Retailing: the Effects of Customer Satisfaction, Loyalty Cards and Shopper Characteristics," Journal of Retailing (79:2), 2003, pp. 97-106.

[33] Melville, N., K. Kraemer, and V. Gurbaxani, "Review: Information Technology and Organizational Performance: An Integrative Model of IT Business Value," MIS Quarterly (38:2), 2004, pp. 283-322.

[34] Meyer-Waarden, L., "The Impact of Reward Personalisation on Frequent Flyer Programmes' Perceived Value and Loyalty," Journal of Services Marketing (27:3), 2013, pp. 183-194.

[35] Mimouni-Chaabane, A. and P. Volle, "Perceived Benefits of Loyalty Programs: Scale Development and Implications for Relational Strategies," Journal of Business Research (63:1), 2010, pp.32-37.

[36] Moos, D.C., and E. Marroquin, "Multimedia, hypermedia, and hypertext: Motivation considered and reconsidered," Computers in Human Behavior (26:3), 2010, pp. 265-276.

[37] Nakamoto, S., "Bitcoin: A Peer-to-Peer Electronic Cash System," https://bitcoin.org/bitcoin.pdf, 2008.

[38] Nunes, J. C., and X. Dréze, "Your Loyalty Program is Betraying You," Harvard Business Review (84:4), 2006, pp. 124-131.

[39] O'Donnell, E., and S. Brown, "Brand Community Loyalty: A Self Determination Theory Perceptive," Academy of Marketing Studies Journal (16:2), 2012, pp. 107-119.

[40] Osbaldiston, R. and K. M. Sheldon, "Promoting Internalized Motivation for Environmentally Responsible Behavior: A Prospective Study of Environmental Goals," Journal of Environmental Psychology (23:4), 2003, pp. 349-57.

[41] Peterson, R. A., "Relationship Marketing and the Consumer," Journal of Academy Marketing Science (23:4), 1995, pp. 278-281.

[42] Polo, Y., and F. J. Sesé, "How to Make Switching Costly. The Role of Marketing and Relationship characteristics," Journal of Service Research (12:2), 2009, pp. 119-137.

[43] Ray, G., W. A., Muhanna, and J. B. Barney, "Information Technology and the Performance of the Customer Service Process: A Resource-Based
Analysis," MIS Quarterly (29:4), 2005, pp. 625-652.

[44] Roehm, M. L., P. E. Bolman, and H.A. Roehm, Jr., "Designing Loyalty-building Programs for Packaged Goods Brands," Journal of Marking Research (39:2), 2002, pp. 202-213.

[45] Royal Bank of Canada, "Blockchain kicks-off new way for business clients to build employee loyalty," http://www.rblockchain.com/newsroom/news/2016/2 0161115-league.html, November 15, 2016.

[46] Ryan, R. M., and E. L. Deci, "Self-Determination Theory and the Facilitation of Intrinsic Motivation, Social Development, and Well-Being," American Psychologist (55:1), 2000, pp. 68-78.

[47] Ryan, R.M., and E.L. Deci, "An Overview of Selfdetermination Theory: An Organismic-dialectical perspective," Handbook of Self-Determination Research. Rochester, NY: University of Rochester Press, 2002.

[48] Sarker, S., S. Sarker, A. Sahaym, and N. BjørnAndersen, "Exploring Value Cocreation in Relationships Between an ERP Vendor and its Partners: A Revelatory Case Study," MIS Quarterly (36:1), 2012, pp. 317-338.

[49] Sheth, J. N., B. I. Newman, and B. L. Gross, "Why We Buy What We Bu y: A Theory of Consumption Values," Journal of Business Research (22:2), 1991, pp. 159170.

[50] Shi, L., A. I. Cristea, S. Hadzidedic, and N. Dervishalidovic, "Contextual Gamification of Social Interaction-Towards Increasing Motivation in Social E-learning," in Proceedings of the International Conference on Web-Based Learning, 2014, pp. 121127.

[51] Shugan, S. M., "Brand loyalty programs: Are they shams?" Marketing Science (24:2), 2005, pp. 185-193.

[52] Swan, M., Blockchain: Blueprint for a new economy. O'Reilly Media, Inc., 2015.

[53] Sweeney, J. C. and G. N. Soutar, "Consumer perceived value: the development of a multiple item scale," Journal of Retailing (77:2), 2001, pp. 203-220.

[54] Webb, A., " 8 Tech Trends to Watch in 2016," Harvard business review," https://hbr.org/2015/12/8-techtrends-to-watch-in-2016, December $8^{\text {th }}, 2015$.

[55] Weinstein, N. and R. M. Ryan, "When Helping Helps: Autonomous Motivation for Prosocial Behavior and its Influence on Well-Being for the Helper and Recipient," Journal of Personality and Social Psychology (98:2), 2010, pp. 222-44.

[56] Woodruff, R. B., "Customer Value: the Next Source for Competitive Advantage," Journal of Academy Marking Science (25:2), 1997, pp. 139-153.

[57] Wyer Jr., R. S., and A. J. Xu, "The Role of Behavioral Mind-sets in Goal-directed Activity: Conceptual Underpinnings and Empirical Evidence," Journal of Consumer Psychology (20:2), 2012, pp. 107-125.

[58] Yin, R.K., Case Study Research: Design and Methods, Newbury Park, CA: Sage, 1994.

[59] Zeithaml, V. A., "Consumer Perceptions of Price, Quality, and Value: A Means-end Model and Synthesis of Evidence," Journal of Marketing (52:3), 1988, pp. $2-22$

[60] Zhang, J., and E. Breugelmans, "The Impact of an 
Item-based Loyalty Program on Consumer Purchase Behavior," Journal of Marketing Research (49:49), 2012, pp. 50-65.

[61] Zhang, T., R. Agarwal, and H. C. Lucas, Jr., "The Value of IT-Enabled Retailer Learning: Personalized Product Recommendations and Customer Store Loyalty in Electronic Markets," MIS Quarterly (35:4), 2011, pp. 859-881. 